\title{
EL PROBLEMA DE LA ESENCIA Y LA EXISTENCIA EN MULÁ SADRA SHIRAZI, CON UNA REFERENCIA A FRANCISCO SUÁREZ
}

\author{
J. A. Antón Pacheco \\ Universidad de Sevilla
}

\section{RESUMEN / ABSTRACT}

El filósofo español Francisco Suárez y el iraní Mulá Sadra Shirazi son estrictamente contemporáneos (s. XVII) y además coinciden en muchos puntos fundamentales de sus respectivos sistemas de pensamiento (naturalmente, no se conocieron). El tema que más los conecta es el de la primacía metafísica otorgada por ambos a la existencia sobre la esencia, al ser sobre la quididad; lo que de alguna manera los hace unos precedentes de la filosofia de la existencia concreta, lo que da lugar a que ambos filósofos valoren ante todo el hecho de ser frente a la universalidad abstracta, que toma así un significado intencional. Siguiendo una indicación hecha por Henry Corbin, en este trabajo se hace una aproximación introductoria al estudio comparado de estos dos autores.

Spanish philosopher Francisco Suarez and Iran one Mula Sandra Shirazi are strictly contemporary authors (17th Century) and they agree in many core concepts in their thought systems (although they did not met each other). Their closer connection is about the metaphysic primacy they gave to the existence over essence, the being over the quid ide. In such a way, they are pioneers of a Philosophy of the specific existence, valuing both authors the being against the abstract universality, taking an intending meaning. Following an indication being made by Henry Corbin, we do in this paper an introductory approach to the comparative study of both authors. 
Henry Corbin en repetidas ocasiones ha señalado la semejanza existente entre Suárez y Sadra Shirazi en lo referente al tratamiento de la esencia y la existencia. También Christian Jambet alguna que otra vez ha planteado el acercamiento entre el filósofo español y el persa. Sin embargo, que sepamos, nunca ha sido abordado el estudio comparativo de ambos pensadores. Existen ensayos en los que se relaciona Mulá Sadra Shirazi con St. Tomás, Leibniz, Hegel, Heidegger, entre otros ${ }^{1}$, pero no conocemos ninguno que explícitamente plantee la conexión Suárez-Sadra, y esto tal vez se deba a la complejidad intrínseca de ambos autores. Sin embargo, creemos necesario emprender aunque sea de manera propedéutica el estudio comparativo.

Francisco Suárez (1548-1617) y Mulá Sadra Shirazi (980/15721050/1640) son, como puede comprobarse, estrictamente contemporáneos, aunque desde luego no hubo el menor contacto entre ellos. Pero las posible similitudes que los aúnan no pueden extrañarnos en la medida en que a ambos los podemos considerar como culminaciones de sus respectivas tradiciones filosóficas: Suárez de la escolástica; Mulá Sadra Shirazi de la falsafa de raigambre aviceniana (tengamos en cuenta además que Suárez leyó al Avicena latino). En los dos casos nos remitimos en última instancia a Aristóteles. Y es que en efecto, Suárez y Sadra desempeñan en el siglo XVII la función de reinterpretadores y catalizadores de sus respectivas tradiciones filosóficas, que en el fondo es la misma tradición: la que va desde Platón y Aristóteles hasta aquellos dos mismos a través de Plotino y todo el neoplatonismo, Alejandro de Afrodisia, Juan Filópono, Temistio, Alfarabí, Tomás de Aquino, Avicena, Duns Escoto, Sohravardi, Nasiraldin Tusi, Mir Damad...

1 Cf. Islam-West Philosophical Dialogue. The papers presentad at the World Congress on Mulla Sadra (May-1995, Teherán) 3 vols., 1381/2002, Teherán. 
El problema fundamental para Suárez ${ }^{2}$ y Sadra Shirazi ${ }^{3}$ (que es el que propicia el cotejo entre ambos) es el de la prioridad metafísica de la existencia sobre la quididad o esencia. El origen de la cuestión se encuentra de manera explícita en Aristóteles ${ }^{4}$ y más en concreto en sus términos tóde ti, ti, tó ti ên eínai, ti estin y en lo que todos ellos quieren significar: el ser de una cosa, lo que una cosa es, el qué es verdaderamente unas cosa. ¿Cómo se tradujeron estas expresiones griegas? Nos encontramos además que el eínai, el ser como existencial, es vertido como wuyûd (y también como kawn). El problema de las traducciones de los términos filosóficos aristotélicos no es solo lingüístico sino sobre todo metafísico, y las ambigüedades, vacilaciones y anfibologias a las que dan lugar esas traducciones obedecen a la misma labilidad del tema, esto es, a la misma labilidad del ser.

2 La obra filosófica más importante de Suárez es Disputaciones metafisicas, edición de S. Rábade Romeo, S. Caballero Sánchez y A. Puigcerver, Madrid, 1960-1966, 7 vols. Existen muchas traducciones parciales y antologías de las Disputaciones. De todas ellas señalamos como más recomendable Francisco Suárez. Disputaciones metafisicas, presentación de Sergio Rábade Romeo, estudio preliminar de Francisco León Florido, Madrid, 2011. De la bibliografia suareziana más reciente recomendamos especialmente Jean-Paul Coujou, La constitution suarézienne de l'unité trascendantale et ses implications antropológico-politiques, Revue Philosophique de Louvain, 108, (2010) 585-615. Una perspectiva novedosa de Suárez puede verse en Salvador Castellote Cubells, Suárez y Picasso. A la búsqueda de una nueva forma de producción artística. A propósito de un libro de Michael Renemann, Anales valentinos 72 (2010) 287-314. En este artículo el autor glosa el libro de Michael Renemann, Gedanken als Wirkursachen. Francisco Suárez zur geistigen Hervorbringung, Amsterdam-Filadelfia, 2010.

3 Las obras principales de Mulá Sadra Shirazi en sus ediciones más a la mano son: Le Livre des penetrations metaphysiques (Kitâb al-Mashâ'ir), traducido, anotado e introducido por Henry Corbin, Lagrasse, 1988; The Elixir of the gnostics (Iksir al-'ârifin), edición de William Chittick, Provo-Utah, 2003; Le Verset de la Lumière, edición de Muhammad Khâjanî-Christian Jambet, París, 2009; Commentaires de Mollâ Sadrâ Shîrâzî en Shihâboddîn Yahya Sohravardî, Le Livre de la sagesse orientale )Kitâb Hikmat al-Ishrâq),traducción y notas de Henry Corbin establecidas e introducidas por Christian Jambet, Saint-Amand, 2003; Henry Corbin, La Philosophie irannienne islamique aux XVII ${ }^{\circ}$ et XVIII ${ }^{\circ}$ siècles, Paris, 1981; Cécile Bonmariage, Le Réel et les réalidades (incluye una amplia selección de textos de Sadra especialmente relevantes para el estudio comparado con Suárez), París, 2007; Christian Jambet, L'acte d'être. La philosophie de la révéletion chez Mollâ Sadrá,, Parîs, 2002; Se rendre inmortal suivi du Traité de la résurrection de Mollâ Sadrâ Shîrâzî, Cognac, 2000; Carlos A. Segovia, Sadr Ad-Dîn Sîrâzî, la filosofia islámica y el problema del ser. Estudio y comentario del Kitâb al-masẩir, Granada, 2005.

4 Cf.Metafísica de Aristóteles, edición de V. García Yebra, Madrid, 1982. 
Aquellas expresiones de Aristóteles a las que haciamos referencia fueron traducidas al árabe por mâhîyya y al latín por quididad, que quieren significar la esencia, el qué de una cosa (mâh, quid, cheh en persa) ${ }^{5}$. Pero aquí comienza ya la ambigüedad, pues ¿qué es el qué o la esencia de una cosas? Además la esencia en cuanto realidad constitutiva de una cosa también puede ser denominada por la palabra griega ousia o por las árabes dhât, huwa hû, 'ain y haqiqá, o por yawhar (que es de origen pahleví) ${ }^{6}$, o por la latina substantia; hay además otro término muy cercano, ontológicamente hablando, a estas nociones como es hypokeimenon y su traducción por subyectum. El mismo Mulá Sadra Shirazi habla de haqa'iq wuyûdiyya y huwiyat wuyûdiyya para referirse a las realidades existenciales concretas, a las ipseidades intrínsecas. Asimismo annîyya, como aysa, sirven para traducir tó ti ên eínai, tóde ti y tó ti éstin, pero sobre todo designan el ser mismo de una cosa, la haecceitas de algo. Todas estas variantes no se deben a deficiencias de ninguna lengua sino a la intrínseca falta de concreción del problema del ser, lo que motiva este tránsito de términos que intentan definir los ámbitos del acontecer ontológico.

Pero se estableció un cierto consenso para denominar tó ti ên eínai como aquello que realmente una cosa es, la esencia o quididad o mâhîyya. El problema, no ya lingüístico sino metafísico, es pues: ¿qué es lo que verdaderamente una cosa es? Si lo que verdaderamente una cosa es, es el ser de una cosa ¿qué es lo que en la cosa pertenece al ser y lo que pertenece a la cosa?; si el ente es lo que consiste en ser ¿en qué consiste el ser y en qué consiste el mismo ente? Pues si el ente es justamente ser ¿qué es entonces el ente en tanto ente? En otras palabras: habrá que distinguir entre la esencia de la cosa y la existencia de esa misma cosa, entre la quididad o mâhîyya y la cosa. Entonces, esta clásica cuestión se formula de la siguiente manera: ¿qué tiene prioridad, la esencia o la existencia, la mâhîyya o el wuyûd? Este es el debate de la filosofia clásica (para nosotros, sencillamente de la filosofia).

5 Cf, Soheil M. Afnan, Philosophical terminology in arabic and persian, Leiden, 1964.

6 Proviene de gôhr-gwh, y en la literatura mazdea tiene ya el significado de sustancia o naturaleza, cf. Dadestan i Denig (ed. de Mahmoud Jaafari Dahaghi), París, 1998. 
Si a la pregunta anterior contestamos que la esencia, hacemos de la existencia un accidente de la esencia o una potencialidad de la esencia; lo que entraña un menoscabo de los existentes pues se convierten en epifenómenos de un universal abstracto. Pero si decimos que la primacía ontológica radica en la existencia debemos preguntarnos qué es entonces lo que diferencia una cosa de otra, pues podemos caer en un monismo igualmente abstracto.

A tenor de esto, hay una tendencia en la filosofia tradicional de afirmar la preeminencia de la esencia sobre la existencia, dado que la esencia significa permanencia y persistencia frente a la delicuescencia de la existencia. Pues parece que los hombres, las mesas y los árboles nacen, pasan y desaparecen, mientras que el hombre, la mesa y el árbol son consistentes (esto es, las esencias hombre, mesa y árbol persisten conceptualmente). Y parece que la existencia (en tanto exsistere, en tanto wuyùd, en tanto salir al encuentro) indica un movimiento incompatible con la solidez de la esencia. Ahora bien, ya aquí se percibe una paradoja que va a dar lugar a que se ponga en cuestión la primacía de la esencia sobre la existencia: la esencia, que es lo que verdaderamente es, no existe; y el existente, que es lo que existe, no es verdaderamente ${ }^{7}$. Y sin embargo, tampoco se puede prescindir de la esencia como si fuera un mero ente de razón, pues las notas nocionales que componen la esencia de algo poseen consistencia interna. Entre otras cosas, a esto se deben esas vacilaciones entre esencia y existencia de las que hablábamos antes. La consistencia de la universalidad de la esencia persiste como realidad ontológica, aunque esa realidad en Sadra (y en Suárez) se deba a una construcción mental legitimada por la existencia misma. Como puede verse, se trata de saber qué es verdaderamente una cosa: el hecho de ser o el hecho de ser tal cosa.

La preeminencia de la existencia sobre la esencia el algo que se entrevé ya en Avicena, St Tomás y Sohravardi. Pero donde se expresa de una forma clara y patente es en Mulá Sadra Shirazi. En efecto,

\footnotetext{
Para todo este tema, ver muy especialmente Étienne Gilson, El ser y los filósofos ( $5^{\circ}$ edición, trad. de Santiago Fernández Burillo), Pamplona, 2009. Henry Corbin hace una síntesis magistral de la problemática de este libro en la Introduction (IV. Aperçu philosophique) a su edición de Le Livre des pénétrations métaphysiques. No olvidemos que Gilson fue el gran maestro en filosofia de Corbin.
} 
en el filósofo persa la quididad real (mâhîyya) es la existencia, el hecho de ser (wuyûid), el actus essendi; o dicho de otra manera: la quididad real es la quididad existente del existente $(\text { mawyûd })^{8}$. El argumento fundamental de Sadra Shirazi es parecido al del tercer hombre: si la esencia prima sobre la existencia, entonces la esencia de alguna manera es o existe (¿qué clase de esencia sería aquella que no es? $)^{9}$. Pero si es o existe también necesitará de otra quididad o esencia que preste esencia a la esencia de esa existencia, y así hasta el infinito. Luego no se puede separar la esencia de la existencia: la esencia real es la dada actualmente en el existente. Por otro lado, si la existencia fuera un mero accidente de la esencia, no habría diferencia entre realidad lógica y realidad ontológica. Y además si la existencia fuera un accidente de la esencia, como todo accidente, deberá de estar en un substrato (en este caso la quididad), pero entonces el substrato de la existencia tendrá que ser otra existencia que sirva de substrato, y así hasta el infinito. En definitiva, aquello que verdaderamente es para Sadra es el ser existente actual y concreto, el hecho de ser. La existencia (wuyûd) no se añade a la quididad (mâhîyya) para constituir el existente (mawyûd): el acto de ser es la quididad existente, la esencia actual; y la quididad entonces solo tiene existencia mental (kawn al-dhihni). Es un concepto intencional. Pero esto no quiere decir que Sadra caiga en la esterilidad del nominalismo. De lo que siempre huye Sadra es de la universalidad abstracta, de la generalidad (en esto lo consideramos muy en la línea de Sohravardi). En el entramado metafísico de Sadra Shirazi las realidades que sirven de principios inteligibles para el desarrollo de los seres cumplen una función determinante: son los Nombres, Inteligencias, Luces, Ideas, Ángeles, es decir, existentes que constituyen metafisicamente a otros existentes.

En Sadra Shirazi el ser no es un predicado sino un verbo existencial, y por tanto no decimos el existente es esto y lo otro (las

8 Estamos dando por supuesto que quididad y esencia son sinónimos, lo cual no deja de ser problemático. La quididad parece que significa la universalidad del concepto y la esencia lo intrínseco de una cosa. Por esto mismo la esencia, quale quid, pueden ser annîyya o huwa.

9 Ya San Agustín percibió con mucha lucidez esto cuando afirma en De civit. Dei, XII, 1 que en realidad esencia es simplemente el hecho de ser. Significativamente, Suárez cita esta referencia de San Agustín en Disp. XXXI, 20. 
notas que marcan su quididad) sino el existente existe, y esto y lo otro son modos que dependen del hecho de ser de ese existente. No hay que decir: el hombre es esto y lo otro, sino es el hombre; el existente no tiene existencia, el existente es existencia ${ }^{10}$. La preeminencia del existir (asalat al-wuyûd) frente a la esencia o quididad significa contemplar el ente desde su pertenencia al Ser. Por el contrario, la preeminencia de la quididad o esencia (asalat al-mâhîyya) termina convirtiéndose en la preeminencia del ente (el qué del ente) sobre su existencia: lo importante entonces es "qué es", no "es"; aquí lo relevante entonces es lo presente y no la Presencia. En la primacía de la existencia sobre la esencia se valora antes que el "qué es la cosa", el hecho de que la cosa "es". Luego la verdadera esencia de todo lo que hay es precisamente "ser" antes que ser esto o lo otro, pues esencia es antes que nada "lo que está siendo". La preeminencia de la existencia significa para Sadra conocer lo presente en su pertenencia a la Presencia ('ilm hozuri), mientras que el conocimiento representativo ('ilm sûrì) será conocer lo presente en cuanto presente, en su función instrumental, en cuanto realidad controlable, calculable y apropiable. La prioridad del significado predicativo del verbo ser frente al sentido existencial motiva que el existir se convierta en algo indiferente y se le dé toda la importancia al ser esto o lo otro, a lo predicativo frente a lo existencial. Plantear la preeminencia de la Presencia frente a lo presente, de la existencia sobre el existente, significa plantear la experiencia del existente en su pertenencia a Dios mismo, en la medida en que para Sadra el ser y lo Divino coinciden.

10 Henry Corbin atribuía este radical ontologismo al hecho de que Sadra, al ser persa y hablar una lengua indoeuropea, concede un valor existencial al verbo budán. Es decir, Sadra lo que nos quiere decir, según Corbin, es hasty hast (el ser existe) y no wuyûdîyat al-mawyûd o mawyûdîyat al-wuûid (ser un ente o un ente es esto y lo otro). No creemos sin embargo que esta sea una circunstancia tan determinante pues nos parece, frente a lo que tantas veces se ha dicho, que los verbos semitas recogen la idea del ser como existencial; y no solo el verbo wuyûd sino también el verbo kawn. De hecho Sadra Shirazi utiliza junto al wuyûd el kawn (takawwn, kâ'inât, mukawwanât, takwîn), si bien este último verbo lo reserva para denominar a los seres contingentes. Como regla general se puede decir que kawn y sus derivados se refieren al ser generado y wuyûd y sus derivados al ser como presencia. Además el cristianismo en lengua siriaca con antelación había elaborado una terminología técnica a partir de las discusiones cristológicas que servirá de plataforma para al Islam de acceso a la filosofia. Lo que al mismo tiempo demuestra la importancia del pensamiento en lengua siriaca en la transmisión de la filosofia griega a la filosofia musulmana sin solución de continuidad. 
Para Suárez, quien en este sentido culmina la tradición tomista, la esencia real es la esencia en acto, el qué de la cosa actual, por tanto la esencia real se da en el existente. En lo particular está lo universal. Resulta así que también para Suárez la esencia es inseparable de la existencia, y solo en cuanto ente de razón la esencia es separable de la existencia. Para el filósofo español la existencia es la misma esencia en la medida que es sustracción a la nada, de igual forma que la quididad como esencia es la determinación nocional del existente. Es decir, el modo particular de ser un existente es su esencia; la oposición a la nada del existente es su existencia. Son dos modos de ver la cosa (esta distinción suareziana está supuesta en toda la obra de Sadra al decir que la esencia es el límite de la existencia). Pero la esencia no añade nada realmente distinto a la existencia: una esencia que no puede existir es un ente de razón. O como afirma Sadra Shirazi, la existencia de Zayd es lo mismo que las determinaciones de Zayd $^{11}$.

Ahora bien, en la cuestión de la primacía de la existencia sobre la esencia, Sadra es si cabe más radical que Suárez, pues para este la quididad real (que es la actual) determina la constitución del existente (aunque sea de forma intencional): pero para Sadra Shirazi el hecho de ser esta u otra determinación depende del hecho mismo de ser. Esto es, el hecho de ser de un existente (la densidad ontológica del existente, su participación en el ser) hace que tenga tal determinación, es decir, tal quididad ${ }^{12}$. Como la quididad es en sí potencialidad e inactualidad, más un ser se acerca a la existencia, más se aleja de la esencia pues hace realidad sus notas existenciales.

Tanto para Sadra como para Suárez no hay distinción real ente esencia y existencia: la esencia real es aquella que se da en

11 Sin duda esto recuerda las conocidas palabras de Aristóteles en el libro IV de la $\mathrm{Me}$ tafisica: "Un hombre, un hombre existente y hpmbre, son exactamente lo mismo".

12 Cf., Paola D'Aiello, La speculazione islamo-iraniana tra Sohravardî e Mollâ Sadrâ Sîrâzî, en Universalità de la ragione Pluralità delle filosofie nel medioevo. XII congresso internazionale di Filosofia Medievale de la Societé Internationale pour l'Etude de la Philosophie Medieval (a cura di A. Musco, R. Gambino, L. Pepi, P. Spallino, M. Vassallo), vol. III (Orientalia), Palermo, 2012. 
el orden de la existencia. La esencia es una forma de existencia en la mente. Se puede afirmar por tanto que ambos filósofos son existencialistas en el sentido más riguroso de la palabra. Consecuencia de todo lo que estamos diciendo es que para Sadra Shirazi el ser no es una noción común sino lo intrínseco de la cosa. Hay una prioridad del wuyûd frente al mawyûd, del ser frente al existente; lo que significa que el existente concreto y particular (el existente actual) tiene que verse no desde él mismo sino desde el Ser que lo hace ser: lo existente es por el Ser, aunque ningún existente sea el Ser. He aquí la diferencia ontológica que exonera al Ser (y para Sadra el Ser es Dios, como dijimos antes) de cualquier quididad (Dios no es un ente) así como de cualquier monismo indiferenciado. Todo lo presente manifiesta la Presencia, pero nada de lo presente es la Presencia. Para Sadra, pues, la primacía del ser quiere decir que frente a la esencia (que es cerrada y estática) la existencia es abierta y dinámica. Y esto hace que podamos entrar ahora en otra dimensión trascendental para la filosofia de Sadra Shirazi. Nos referimos a la teoría de la intensificación de las formas, a la modulación del ser, al tashkik al-wuyûd. Justamente porque la existencia es apertura (al contrario que la esencia) el existente puede modularse y ser más ser ser. Esta idea marca la intención última del pensamiento sadriano, que consiste en que el alma adquiera su propia intensidad existencial. Y esto equivale a un progreso en la compleción del alma a través del conocimiento y de la vida espiritual (la teoría del conocimiento está aquí incluida). Para Sadra ser y pensar se identifican, luego ser cada vez más ser es ser cada vez más pensar; es decir, ser cada vez más la existencia que es el ser actual. Y por tanto ser cada vez menos esencia (o depender menos de la potencialidad de la esencia).

La metafísica de Sadra Shirazi se desarrolla más en términos de acontecimientos que de sustancias. Esto refuerza nuestra idea de un Sadra profundamente aristotélico (contra lo que pueda parecer). Pues en efecto, lo fundamental en Aristóteles es la forma en cuanto aparición o presencia: éxtasis, apofánsis o emergencia al ser; y en la teoría de Sadra sobre el movimiento de la sustancia (harakat yawhariya) lo que encontramos es un reflejo de la primacía del ser, pues aquí movimiento sustancial significa prioridad del acontecimiento en su continuo aparecer. 
La esencia en sí misma es una falta de actualidad y realidad, pues lo verdadero es la existencia actual. Compárese esta idea compartida por Sadra y Suárez con la conocida frase de Avicena: "La esencia no merece la existencia"13. Esto es así porque el mero hecho de que podamos establecer una composición en los existentes entre esencia y existencia indica la indigencia ontológica de los existentes, pues lo que la distinción misma muestra es su falta de compleción o plenitud metafísica. Sólo en el Principio supremo existencia y esencia se identifican: para Dios su esencia es el hecho mismo de ser. Por eso no es un mero ente de razón la esencia ni tampoco el universal lógico: hay una justificación ontológica de la esencia basada en el carácter potencial (y contingente) del existente. En este sentido Avicena ${ }^{14}$ significa un momento importante en el trayecto que conduce a la experiencia de la primacía de la existencia sobre la esencia. El problema de la esencia y la existencia en Avicena depende del principio de causalidad absoluta del Ser Necesario: la esencia en sí misma no merece la existencia porque depende del Ser Necesario para hacerse realidad; luego no hay precedencia de la esencia sobre la existencia, sino dependencia de ambas con respecto al Ser Absoluto. La accidentalidad de la existencia en Avicena hay que entenderla con respecto a Dios en tanto

13 Esta frase tiene una sorprendente similitud con esta otra del Fusus al-Hikam de Ibn Arabí: "La esencia no posee el aroma de la existencia". Es muy significativa esta cita akbariana que aparece en varias obras de Sadra (cf. Bonmariage, op. cit., p. 183, n. 7), pues manifiesta de qué manera el propio Ibn Arabí se inserta en la tradición que afirma la primacía de la existencia y además insiste en el carácter existencial de la filosofia sadriana. En este sentido nos alineamos junto a Cecile Bonmariage (especialmente en Elements pour la comprensión de la notion de Tashkîk chez Mullâ Sadrâ, en Islam-West Philosophical Dialogue, vol. In, Christian Jambet (especialmente en "L'essence de Dieu est toute chose". Identité et différence selon Sadr al-Din Shîrâzî, en Le shî'isme imâmite quarante ans après. Hommage à Etan Kohlberg, Turnhout, 2009) y a Carlos A. Segovia (y en última instancia junto a Corbin) al considerar tanto a Ibn Arabí y Sadra como completamente alejados de cualquier sistema de identidad absoluta.

14 Sobre Avicena cf. Metafisica. La scienze delle cose divine (a-Ilâhiyyât) dal Libro della guarigione (Kitab al-Sifâ'), edición del texto árabe, prefacio y revisión del texto latino de P. Porro, traducción de O. Lizzini; La Metaphysique du Sifâ' (2 vols.), ed. de G. C. Anawati, París, 1978-1985; Cuestiones divinas (Ilâhittât), edición de Carlos A. Segovia, Madrid, 2006: Henry Corbin, Avicenne et le Récit visionnaire, París, 1979; Manuel Alonso Alonso, La A-Anniyya y el Al-wûyûd de Avicena en el problema de la esencia y la existencia, Pensamiento 59 (1959) 375-401. 
ser necesario, ya que la misma distinción existencia-esencia denota contingencia. Como deciamos, al igual que Avicena, St. Tomás es otro puntal fundamental en el desarrollo de la idea de la prioridad de la existencia sobre la esencia ${ }^{15}$. Y de la misma manera Sohravardi, quien influye decisivamente sobre Sadra no sólo en la reducción fenomenológica que éste lleva a cabo en su concepto de conocimiento presencial ('ilm hozurî) al ayudarse para ello de la metáfora sohravardiana de la luz como realidad presente para sí misma ${ }^{16}$; sino que también influye en la misma consideración de la preeminencia del ser sobre la quididad, pues es muy cuestionable que Sohravardi propusiera de manera clara y tajante la primacía de la quididad sobre la existencia. Por el contrario, de una lectura de la parte primera de la Sabiduría de la luces deducimos más bien que la existencia es un término general y que el existente actual coincide con su quididad ${ }^{17} Y$ es que para el Jeque Torturado la quididad no se entiende en el sentido de universalidad abstracta sino como lo que una cosa es, el ser de la cosa. La prioridad de la esencia significa la prioridad de la esencia existente. Esto justifica que Sohravardi otorgue tanta importancia

15 Cf. De ente et essentia, texte établi d'aprés les manuscrits parisiens. Introduction, notes et études historiques par M-D Roland-Gasselin, París, 1948; El ente y la esencia, traducción del latín, prólogo y notas de Manuel Fuentes Benot, Buenos Aires, 1977; David B. Burell, Thomas Aquinas (1225-1274) and Mulla Sadra Shirazi (980/1572-1050/1640) and the Primacy of esse/wujûd in Philosophical Theology, Medieval Philosophy and Theology 8 (1999) 207-19; Existence Deriving from the Existent: Mulla Sadra with Ibn Sînâ and al-Suhrawardî, en Avicena and his Legacy (edición de Y Tzivi Langermann), Turnohut, 2009.

16 No se ilumina la luz, la luz de por sí es ya iluminación; pensar un pensamiento es estar ya en el pensar; el ser como luz y pensar es el hecho mismo de aparecer; el conocimiento presencial es el hecho mismo de estar presente como lo que aparece en lo que aparece, en su puro aparecer. El conocimiento presencial es conocer desde la Presencia antes que desde lo presente. En Sadra Shirazi encontramos una auténtica reducción fenomenológica. El conocimiento presencial coincide en gran medida con los planteamientos más extremados de la fenomenología, cf. Eugenio Silverio, Michel Henry: fenomenología de la vida inmanente. Una introducción (trabajo para la obtención del DEA), Universidad de Sevilla, 2009.

17 Cf. Suhrawardî, The Philosophy of Illumination, edición a cargo de John Walbridge y Hossein Ziai, Provo-Utah, 1999; Le livre de la sagesse orientale (Kitâb Hikmat alIshrâq). Commentaires de Qotboddîn Shîrâzî et Môlla Sadrâ Shîrâzi, traducción y notas de Henry Corbin, establecidas e introducidas por Christian Jambet, SaintAmand, 2003. 
a su complejo sistema de Luces y Formas arcangélicas, que no son esencias abstractas sino quididades existentes.

De alguna forma podemos establecer una analogía entre los tres estados del ente en Suárez (el ente en estado absoluto, el ente en estado de mera posibilidad, el ente actual de la existencia) y en Sadra Shirazi (Ser Necesario, existencia desplegada, existencia determinada) en virtud de la reducción del binomio esenciaexistencia a la condición de contingencia frente al Ser Necesario. En efecto, Ser necesario (wâyib al-wuyûd) y ser contingente (munkin alwuyûd) son dos nociones claves para entender a Sadra y a Suárez (he aqui la presencia aviceniana ejerciendo su influencia en ambos filósofos) y en concreto para entender cómo la contingencia que imprime la esencia hace necesaria la actuación de una Causa que siendo puro Ser hace ser a todo lo contingente.

También coinciden Sadra Shirazi y Suárez en la valoración metafísica del individuo concreto, de la existencia actual, de la diferencia y de la forma ante la potencialidad, ante la generalidad del género y ante la inactualidad de la esencia que se colocan en el ámbito del ente mental y de la universalidad abstracta. Al pertenecer la esencia al orden de la contingencia, la esencia es noser y potencialidad. Se manifiesta aquí la profunda raíz aristotélica de ambos autores ${ }^{18}$. Para Sadra como para Suárez, el género, la especie y el universal no tienen otra realidad que la mental. La universalidad y la generalidad son abstracciones, conceptos aplicados por el intelecto al existente; forman precisamente su quididad. Esta es, pues, el modo interno de ser la realidad externa o existente. En Suárez los mismos trascendentales son ciertamente propiedades reales, pero distinguibles del ente individual y concreto en tanto entes de razón: todo lo que existe es individual y concreto,

18 No parece que Étienne Gilson haya conocido la filosofia de Mulá Sadra Shirazi, pues en caso contrario habría visto en él a un verdadero pensador de la existencia, cualidad esta que el filósofo francés solo reserva para St. Tomás. Por otro lado, la reivindicación que Sadra lleva acabo del existente concreto lo acerca de manera extraordinaria al Enkelte de Kierkegaard. En efecto, creemos que Sadra Shirazi es el filósofo idóneo para poner a dialogar con Kierkegaard, pues la preeminencia de la existencia sobre la quididad significa la preeminencia del individuo sobre lo general. 
y los universales están en los propios entes individuales. Cuando Suárez utiliza el argumento del tercer hombre para hacer coincidir unidad y ente (pues en caso contrario habría que postular una unidad de la unidad y así hasta el infinito), lo que nos quiere decir es que no hay que dividir un trascendental del ente, puesto que rige siempre la primacía de lo singular; luego el ente y la unidad son convertibles. Por tanto, podemos hablar para ambos autores de un individualismo metafísico basado en la preeminencia del hecho de ser. Lo que hace al ser real es la diferencia.

Las formas existenciales son modos de ser, lo que concilia este pluralismo ontológico con la unidad del ser. En Sadra, univocidad $\mathrm{y}$ equivocidad se reconcilian mediante la analogía que, como en Suárez, constituye la estructura lógica y ontológica de la realidad $^{19}$. El problema filosófico para Sadra y el que va delineando su transcurrir especulativo es el que ya se planteó Platón en la segunda parte del Parménides: cómo afirmando lo Uno tiene que admitirse también lo Múltiple; cómo experimentando lo Múltiple tiene que postularse necesariamente lo Uno. La unidad del ser en Sadra no alude a una disolución de las diferencias sino más bien a todo lo contrario: es la unidad real la que posibilita las existencias particulares (wuyûdatjassah). En Sadra hay identidad y diferencia.

Pero en Mulá Sadra Shirazi la prioridad de la existencia sobre la esencia (que es lo que lo asemeja a Suárez) está en función del tashkik o modulación del ser. Y entonces la falsafa se hace 'irfan (si es que alguna vez ha dejado de serlo), es decir, gnosis o experiencia continua de las transformaciones del existente en más ser, forma, luz o pensamiento, más allá de la muerte. Y entonces los interlocutores de Sadra son Jacob Böhme y Emanuel Swedenborg. La modulación del ser o el movimiento substancial (harakat jawhariya) en Sadra equivale a lo que Corbin (parafraseando a Heidegger) denomina "ser para más allá de la muerte". Y sin embargo, podríamos encontrar aquí otro posible punto de encuentro con Suárez en su noción de potencia

19 Suárez fue el gran teórico de la analogía. Cf., José Hellín, De la analogía del ser, según Suárez, Pensamiento, $n^{\circ} 7$ (1946) 267-295. 
obediencial $^{20}$. Ciertamente este concepto se entronca en un contexto teológico cristiano muy concreto cual es el problema de la gratuidad de la gracia que en principio es ajeno a Sadra Shirazi. En efecto la cuestión que se le plantea a Suárez, intentando resumir en extremo, es la siguiente: la gracia, como su nombre indica, es pura donación gratuita de Dios; ahora bien, si un ser es capaz de recibir la acción gratuita de la gracia divina es porque de algún modo está capacitado (aunque sea potencialmente) para recibir esa gracia; por lo que entonces la gracia misma no sería pura gracia sino que respondería a la naturaleza de aquel ser. Es decir, aquí se plantea el conflicto entre lo natural y lo sobrenatural, conflicto que a nuestro juicio desgarra la conciencia de la cristiandad moderna y occidental. Y bien ¿cómo resuelve Suárez esta aparente contradicción? Pues precisamente la potencia obediencial es un intento de salvar esa escisión por parte de Suárez. Sin entrar lógicamente en este intrincado problema diremos tan sólo que con la idea de potencial obediencial Suárez quiere mostrar la posibilidad que todo existente tiene de ser causa instrumental de Dios. En todo hay una potencia obediencial activa para actuar como instrumento divino. La potencia obediencial no es ni exclusivamente natural ni exclusivamente sobrenatural, es una especie de mediación entre ambos estados, lo cual nos indica que para Suárez la existencia (y en especial la del ser humano) es una realidad abierta, susceptible de recepción, transmutación y modificación (precisamente por la acción de la gracia). Pues bien, tanto la modulación del ser de Sadra Shirazi como la potencial obediencial de Suárez coinciden en que presuponen una apertura del ser y una capacidad de transformación basada en la propensión de todo lo real hacia la forma y el acto. Es evidente que la estructura aristotélica del pensamiento suareziano posibilita este razonamiento, como también es evidente que es una causa teológica, específicamente cristiana, la que conduce la reflexión

20 Cf., Juan Roig Gironella, La Potencia obediencial en Suárez, en los confines entre filosofia y teologia, Pensamiento $n^{\circ} 65$ (1961) 77-87. Este autor habla de la potencia obediencial como "un injerto de lo sobrenatural en lo natural". Más recientemente Karl Rahner ha vuelto a poner de actualidad el tema de la potencia obediencial en el contexto de la discusión sobre lo natural y sobrenatural (Blomdel, Henry de Lubac), cf. José Luis Martín Garcia-Alos, El existencial sobrenatural. Clave interpretativa de la antropoteología de Karl Rahner, Barcelona, 1993. La potencia obediencial es también un concepto muy aprovechable por el ecumenismo, y en concreto por la teología del cumplimiento, cf. Pedro Rodríguez Panizo, Disonancia acorde. La significación teológica de la historia de las religiones según R. C Zaehner, Madrid, 2007. 
de Suárez. Pero a la postre existe aquí un motivo más que puede proporcionar razones para comparar a Suárez con Sadra: en ambos el ser humano es una realidad dinámica, fluyente y en continua apertura a nuevos horizontes de existencia.

Una consecuencia evidente de todo lo que hemos visto de manera sucinta es que no se puede mantener de ningún modo la idea de que la falsafa acaba con Averroes o todo lo más con Ibn Jaldún, sino que continúa en el islam iranio, llega a su plenitud con Mullá Sadra Shirazi y prosigue con todo esplendor en las escuelas de Isfaján y Masad con proyección en las filosofias musulmanas de la India y China (independientemente de que pueda seguir habiendo reflexión filosófica en otros ámbitos del Islam). 